\title{
Challenges on Educational Policies Related to the English Teacher's Training
}

\author{
Ramirez Valencia Astrid ${ }^{1}$, Gonzalez Ocampo Diana Katherine ${ }^{2}$ \& Caicedo Saldaña Heberth ${ }^{3}$ \\ ${ }^{1}$ Universidad Distrital Francisco Jose de Caldas, Faculty of Science and Education, Bogotá, Colombia \\ ${ }^{2}$ Unidad Central del Valle del Cauca, Faculty of Science and Education, Tuluá, Colombia \\ ${ }^{3}$ Unidad Central del Valle del Cauca, Faculty of Science and Education, Tuluá, Colombia \\ Correspondence: Ramirez Valencia Astrid, K 3 a 26 a 40, Science and Education, Universidad Distrital, Bogotá, \\ Colombi. \\ Gonzalez Ocampo Diana Katherine, Cra. 21 \#21151, Unidad Central del Valle del Cauca, Tuluá, Colombia. \\ Caicedo Saldaña Heberth, Cra. 21 \#21151, Unidad Central del Valle del Cauca, Tuluá, Colombia.
}

Received: October 20, 2018 Accepted: December 3, 2018 Online Published: December 7, 2018

doi: 10.5539/elt.v12n1p48 URL: https://doi.org/10.5539/elt.v12n1p48

\begin{abstract}
The last events developed in the dimension of teachers' training have defined new rules which they must be trained in. This article points out some aspects and considerations that emerged from the resolution 2041, on February $3^{\text {rd }}$, 2016, which introduces different perspectives that must be taken carefully into account, and an analysis, specially due to the repercussions and implications that Colombian teaching programs have.
\end{abstract}

Keywords: competence, training components, content, teacher training

\section{Introduction}

It is necessary to start clarifying the tendency, by the Ministry of Education, of stating reforms in the English teachers' training process, as result of the deficiencies in the previous processes along a period of time, in relation with the future teachers; it has found, for several times, multiple failures in this phenomenon, identified in the different gauges made by different governmental institutions, as well as teacher's communities, which receive training, being also makers of their process.

\section{Methodology}

In this respect, the approach used for this study was qualitative in the light of a desk-based research by reviewing the current resolutions and educational documents related to the English teacher training processes. Particularly reflecting the Promulgation of a resolution, which has forced to generate major changes within the programs that educate the English teachers, in the Colombian context on its implications and scopes.

\section{New Perspective About English Teacher Training}

The National Ministry of Education (From this moment as MEN), currently, emits the resolution 2041 on February $3^{\text {rd }}, 2016$ that determines a serial of parameters which must be considered by the educational institutions that train teachers in Colombia.

To have a better clarification about this resolution, it is necessary to present some factors that evidence a major tension by the multiple opinions generated around the elements that are part of the education received by teachers, in the different educational faculties, from University institutions.

\section{Qualification}

To start, the degree titles given to the English teachers must be different, in comparison with the titles provided by current educational institutions. In this sense, Figure 1 illustrates the new degrees offered to the English teacher. 


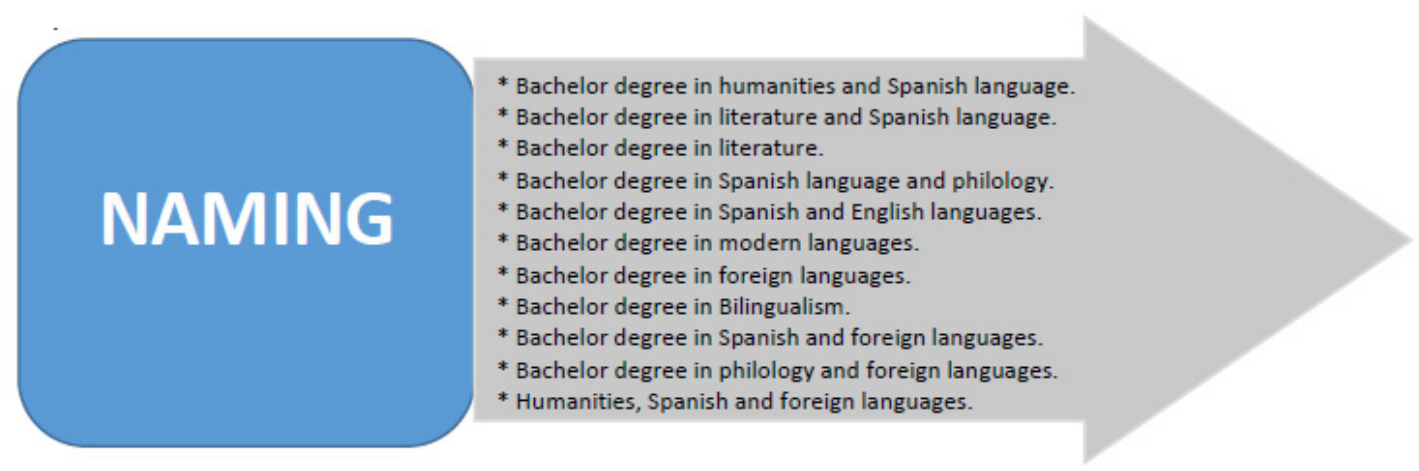

Figure 1. Name of the possible degrees offered to the new English teacher. Source: Own

It means that, the degrees are directly related to the action field in which the future English teacher will be immersed, as a consequence, the institutions that train the English teachers will have to decide for one of them, it is important be conscious about the implications of this change in the curriculum that are taken by these English future teachers.

As a consequence, it is necessary to make some concerns related to the curricular contents and the teacher's competences, that the future teachers must acquire based on the Standard Basic Competence that is taken as a reference for organizing the curricula.

For this reason, the scientific knowledge provided to the future English teacher is focused on the development of the professional training, specially centered in the dimension of the pedagogical practicum, where, according to MEN, it is the most adequate space to achieve a high pedagogical performance, starting from the statement "Learning by doing".

Consequently, the curriculum must be designed, considering the components presented in Figure 2.

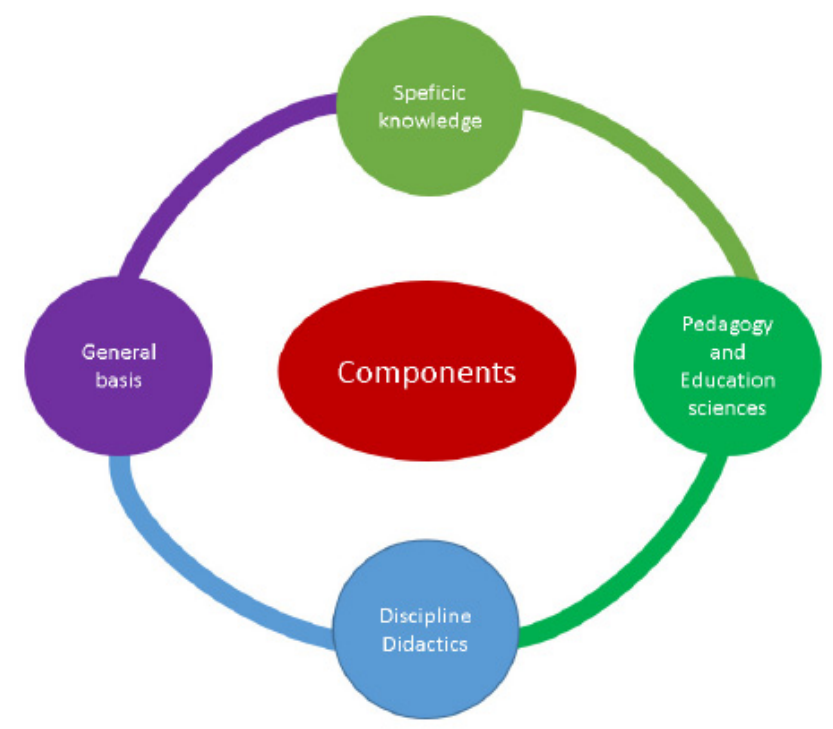

Figure 2. Training competences. Source: Own

This, largely contradicts some postulates of widely recognized authors such as Wallace (1998), who points out that "professional-level practice would be merely an instrumental nature, in which future teachers will simply apply the knowledge developed by experts related to different theories of teaching, didactics, pedagogy, so that they can be applied in the classroom, but with little possibility of development of new knowledge, unless they leave their classroom and become scholars" (p. 76). This argument establishes a differentiation between thinkers, 
scientists, pedagogues, and philosophers as well as applicators of theory (professors, teachers in training) which leads us to a disarticulation, among the great producers of theories and applicators (teachers) of the theoretical principles, creating a gap between knowledge and reality.

Taking this perspective, it is the author who explains, knows, speaks, and emits knowledge, while the teacher is considered as unaware of knowledge; therefore, the teaching process is reduced to a unidirectional communication, which precludes the development of peer dialogue, reflection, interaction and recognition of each other's viewpoints.

For this reason, it is part of the lack of expectations and particular interests by those who wish to learn by departing, on the contrary, an exaggerated need to learn content possessed by the teacher.

Therefore, the most important are the contents of the matter provided by the knowledge that the teacher possesses, in such a way that the teacher will be waiting for some authors, especially foreign producers of principles and didactic strategies related to the English language.

As a result, the teacher is an expert in the knowledge taught, which enables him to transmit the concepts learned from different authors. This conception, is evidenced first of all by the curricular design based on competences defined by the project DeSeCo by the Organization for Economic Cooperation and Development (OCDE in Spanish) (2002) as the capacity to respond to the individual or social requirements or to carry out an activity or a task.

Each competition lies on a combination of interrelated practical and cognitive skills, knowledge (including tacit knowledge), motivation, values, attitudes, emotions, and other social and behavioral elements, which can be mobilized together, to act in an effective manner.

In other words, this agreement of the Ministry of National Education specifically includes the knowledge that the future English teacher should learn, therefore, the training institutions will have to direct their curricula towards the topics included in the different components, within which the curriculum should be designed, as illustrated in Figure 3.
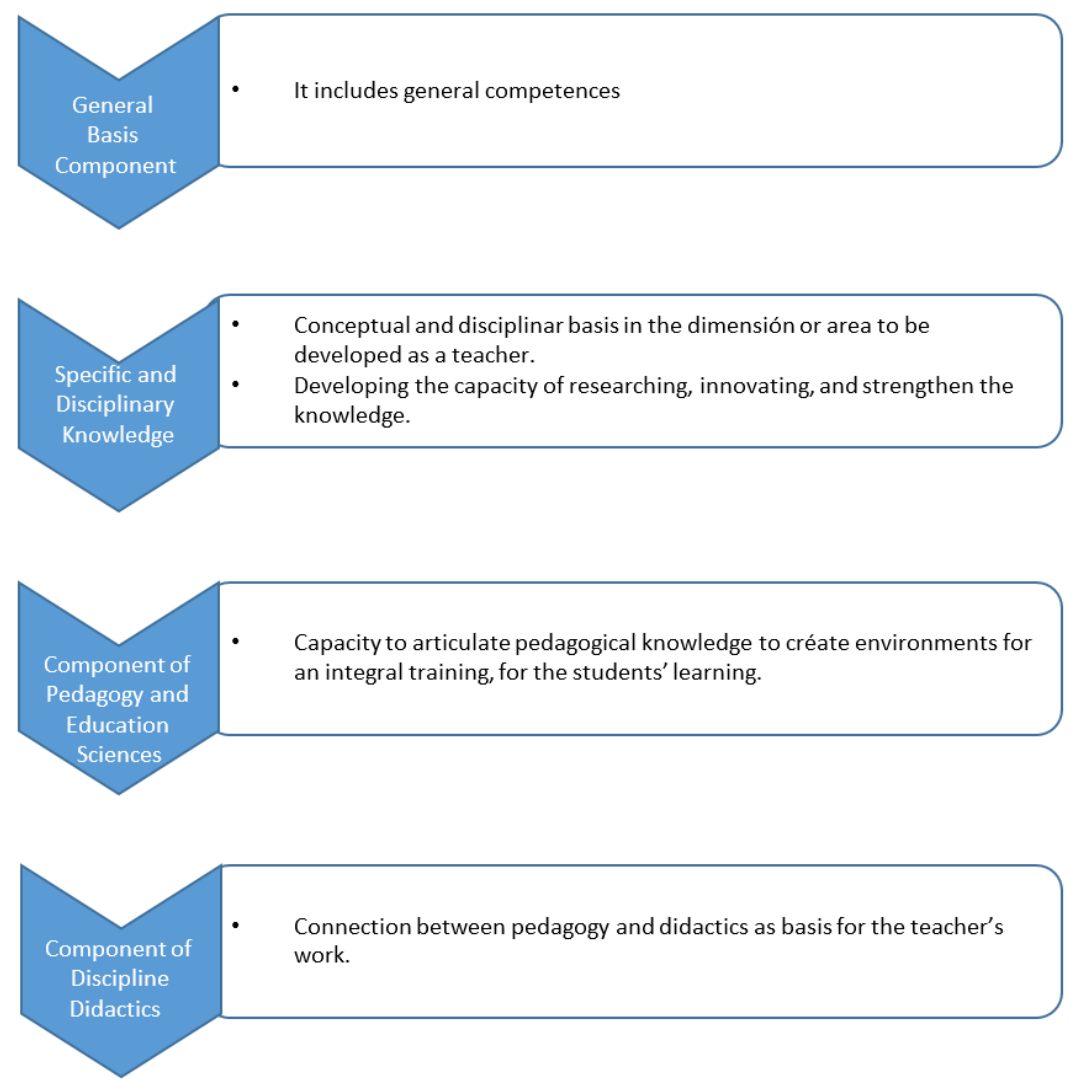

Figure 3. Contents of the training components. Source: Own 
Continuing with this perspective, it is pertinent to mention Kumaravadivelu (2003) who considers that, in establishing this type of connection between the teacher and the theoretical expert, only a hierarchical relationship is promoted between the theoretical expert and the professor, within which not only minimizes any meaningful dialogue between them, but is promoted a certain degree of lack of mutual respect.

In this sense, it lacks any importance the treatment that can be established between teachers and the generators of the theories giving greater relevance to the transmission of the knowledge by the future professor, who is regarded as the player of a knowing produced by the experts within which there is no place for a relationship of interaction, or recognition of the importance of teachers, their experience, or knowledge, the result of their pedagogical exercise.

In this type of training, there is a tendency to use the mastery of the chair, used as a pedagogical resource especially during the development of the classes, minus importance to the reflective teaching, where the professor as a researcher considers that any situation that happens in or outside the classroom can become an opportunity to learn and rebuild his pedagogical exercise.

In summary, in these conditions it can be defined that the activity of the future English teacher is considered as an act of repetitive learning in which the most important thing is to learn by imitating a model, having more relevance the dominance of the aspects of pedagogical management inherent in the teaching exercise.

As a consequence, taking into account this resolution, the most notable is the longer time within which the teacher can be immersed in the school, hence the need to employ 50 credits corresponding to the dedicated curriculum, to the pedagogical component.

It is evident that these type of norms give less importance to aspects such as the attitude of the student, the situations that occur in the classroom, the historical moment in which he / she is living and all the other elements that belong the pedagogical day life in the school.

In the same way, the importance of the interaction between students and students, students and professors, professors and students, professors and professors, professors and school, school and context, and all the other relationships raised in the educational scenario; aspects provocative of criticism and reflection by the teacher, facing his / her work; in the same way, it does not highlight the possibility that the teacher has to rebuild, re-imagine and remake

Considering this statement, it can be affirmed that the teaching practice is conceived, under the application of knowledge that has not been developed by the teacher her/his self, but by academics and theorists, in which the teacher is recognized as a replicator of methods, or an applicator of theories which emerged outside the real school context, instead of being a creator of methodologies, strategies, ways and models of presenting knowledge. By this way, it also denies the possibilities of responding the different demands by the contexts in which he / she has been trained.

In the same vein, teacher training programs may not be virtual. This decision is taken by the importance given to the space of the teaching practice, which requires the permanence of the teacher in front of a group of students because, as already mentioned, one learns to be teacher doing.

This agreement also emphasizes the need to develop skills in the future English teacher, as a result, explicitly and specifically include the development of the following competencies within each of the components, as Illustrated in Graphic 4.

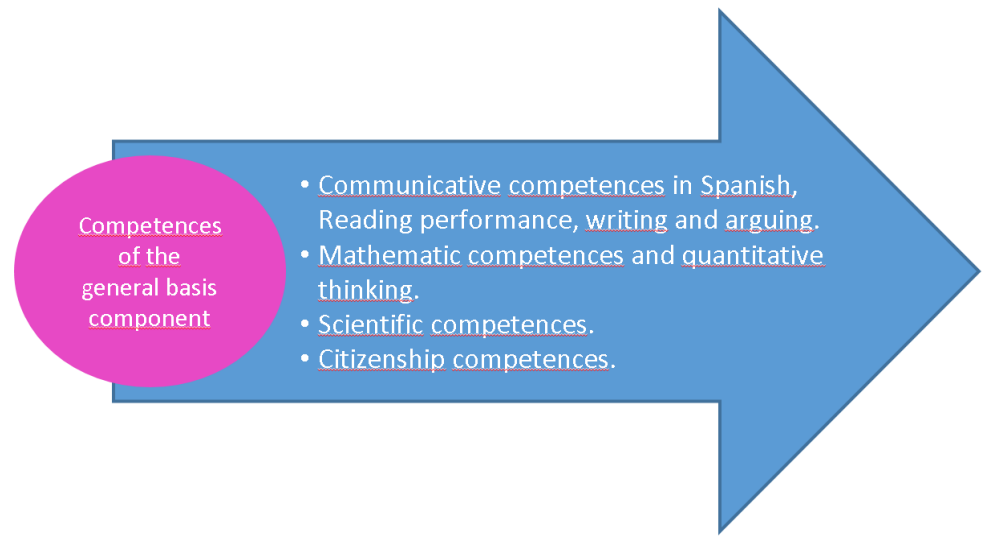

Figure 4. Contents of the general basis component. Source: Own 


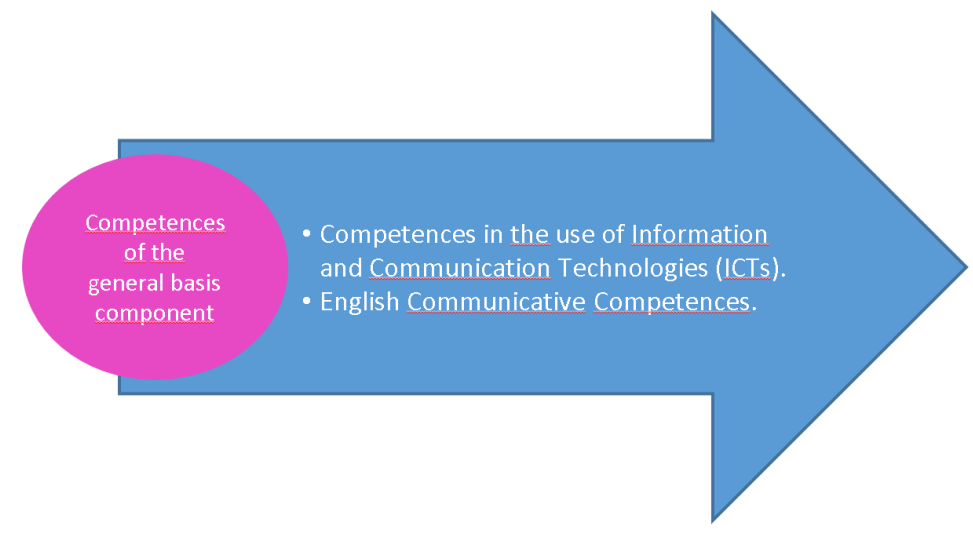

Figure 5. Contents of the general basis component. Source: Own

Therefore, the teacher needs to have a solid training that not only makes him / her ready to share knowledge previously acquired, without considering other multiple factors occurred inside or outside the classroom. For this reason, it demands the implementation of a training model which allows the future English teacher to be in the capacity of devise, respond, generate and adapt new teaching ways, taking into account the considerations by the context which is very changing, mobile and inconsistent, resulting as implausible, as the resolution forces the teacher's training programs respond to a curriculum based on competences, orienting these processes to a domain of the contents which must be taught in the practice; context which is also important in this resolution.

Because of this argument, it is established within the resolution that in the undergraduate programs the following thematic axes should be included: training in pedagogy, didactics of school knowledge, disciplinary and investigative training, both pedagogical and in specific knowledge.

As mentioned previously, it acquires greater importance the space of the teaching practice, the aspects related to the evaluation and the management of a foreign language with which, it is expected to respond to the policies of bilingualism in our Colombian context.

However, it cannot be denied as the condition of being a teacher has many more implications than is apparently perceived; therefore, for this situations it is needed to include a theoretical and a practical preparation based on the practicum because it let students to be in contact with the reality, as a consequence, future English teachers need to be integral and reflective teacher; that allows them to be involved in a permanent update, with the possibility of a professional growth, that brings an expansion of the vision of the reality perceive in the school.

In the same way, it is expected that this condition will lead the teacher to be a change manager in the educational field, through the implementation of experiences of innovation, creation and development of strategies, with which it will be possible to propose other of teaching ways that respond to the needs of the Colombian society.

It is clear how, although current teacher training programs must meet quality standards, there is still an instrumental or skill-building training in teachers, evidenced by the parameters set out in resolution 2041, which leads, as Richards (2012) proposes, proposing unimportant activities, for his work as the English teacher.

For the case study of this article, that is directly related to the training processes of the English teacher and taking into account the criteria established in resolution 2041, the follow-up to teacher training should be directed towards the preparation of the class plans to be executed, usually carried out following a few steps, that allows to have a good performance in the classroom to the future teacher.

On the other hand, it does not deny the importance of a domain of the foreign language, as stablished by Richards and Rodgers (2012) when clarifying how having a good language level permits using the English language in a communicative way, because this knowledge is vitally important, specially by the conditions currently demanded to be teachers, framing bilingualism, in which we are immersed in Colombia; however, it takes the risk that the teacher becomes a subject who consumes theories, instead of being a creator of them.

Additionally, we also find another direction in this resolution; it determines the English teacher also must be trained to manage pedagogical instruments which will improve its performance in the classroom, but as Nunan (2005) states, the teacher must be immersed in a process of knowledge transmission; he / she only has the possibility to obey the processes allowed to learn. It indicates us that the teacher will have to respond to some theoretical precepts acquired during the course of his learning as a teacher, which unfortunately restrict them, by 
having to respond to standards and competencies that is obliged to acquire and teach.

For our particular Colombian case, we do not take into consideration aspects such as those established by Sánchez (2004) who consider that in our specially district schools and schools there is another series of difficulties such as the size of the groups, the lack of teachers, the limited possibilities for the use of English in real situations of communication, among many other situations that the teacher should be prepared to solve.

However, this type of norms does not foresee these situations, nor determines the way in which the future English teacher should be ready to learn to think, to solve, to propose solutions against difficulties like those previously mentioned.

As a consequence, this type of norms aims to the concept of instrumental learning, being in charge, specially of the foreign language level that the future teachers must obtain; they are trained to be classroom teachers, not to be researchers or make academy; to be theory consumers, instead of producing it or be conscious of the need to be immersed in a process of development and permanent training, and for acting in this new global context.

In this order of ideas, it is evident how the training expected to be received by the teacher, according to this resolution 2041, does not approximate, as Graddol (2006) establishes to the models of formation in a global context, that allow to develop as a universal citizen, in response to the needs of people's global relations, which comprise the reality of the academic community; it only forms in three components: language, pedagogy and instrumental research.

As consequence, in this norm, it only considers that the English teacher has a good pedagogical performance in the classroom, without taking into account that the current teachers training programs are responsible of the way to teach, when to teach, where to teach, and the conditions and other relevant aspects in the teacher's work, highlighting the responsibility to involve the teacher in a permanent training program which allows to be responsible of its own learning process along the whole life.

In other words, it is not being formed as Burns \& Richards indicates (2009) to be an integrated teacher to the different academic communities, which allows him to have a constructive interaction in the context in which he is immersed.

Similarly, it is also not considered, as Larsen-Freeman (2012) notes the previous knowledge possessed by the teacher and the role that plays this within his training process, as well as the analysis of the mental processes that the teacher has, the role that he/she plays in the social and institutional context within its process of learning to teach.

On the contrary, the English teacher should be formed as is defined by Kumaravadivelu (1994) as a teacher who transforms and integrates the knowledge society, capable of transforming the relationship between theory and teacher by providing knowledge, skills and autonomy.

Thus, it is needed to consider the importance of the knowledge society and globalization as a socio-economic phenomenon, which has generated new training needs, within which the English teacher is considered as an integral part of networks of academic work, that let him/her be involved in professional groups that are interested in the problems that occur inside or outside the school.

In other words, as Kumaravadivelu (2012) explains, teachers must become strategic teachers and researchers looking to devote a considerable amount of time and effort in the following tasks: firstly, reflecting about the specific needs, wishes, situations and learning - teaching processes; secondly, amplifying their knowledge, dexterity and attitude to keep being informed and involved; and finally, exploring and extending the macro strategies to overcome the challenges involved in changing the teaching contexts; at the moment of designing them adequately, with the aim to promote learning in the classroom, by controlling significantly the capacity of reaction in front of a great variety of possible situations.

As a result, teachers are expected to be able to be part of academic communities where the practice of classroom situations are discussed, so that the English teacher is able to be involved in the teaching and learning process to improve the training process.

To summarize, this reform raises five important elements to be taken into account in the undergraduate programs. The first one specifies that "practice makes the teacher" as expressed by this resolution, which if compared with the previous curricula, within which the practice was obligatory for one year, however each institution was autonomous to make decisions against the period of practice so in this new reform the teacher training is going to dedicated to the practice most of the time.

It means that graduate training programs are currently being forced to introduce the practice from the third or 
fifth semester until they finish their training process. This will bring, a different connotation to the space of teaching practice because it obliges training institutions to create training programs that contemplate new practical aspects within the curricula.

The second aspect considers that the teachers must be bilingual, as a consequence, future teachers will have to domain a second language, for this reason, they must achieve a high performance, corresponding to the level B1, taking into account the criteria considered in the Common European Framework of Reference. In the same way, it will demand that the future English teacher must demonstrate having the B1 level in English language, in order to respond to the demands from the global world, satisfying standards with which the teachers probably will be more competent according to the requirements asked by the institutions where he/she will be probably working.

Thirdly, it prohibits the implementation of virtual teaching programs for the English teachers, because this modality does not allow them to acquire the enough training in the teaching field that let him/her to be considered as an expert teacher. For this reason, the MEN (2013) explains how bachelor programs will have to be offered totally, in a face-to-face modality, emphasizing, at the same time the role of the teacher uncharged of the practice who must be an advisor that guides the future teacher performance as a teacher.

It is necessary to see, if this purpose can be achieved or not, because, although the accompaniment made by the teacher of the course in some cases, it is notable too, that this purpose is not achieved, because in some cases, the practitioner is seen as the substitute teacher, for this reason, it is so common for the practitioner to be considered as the principal teacher in the classroom.

Fourthly, it is evident the change made by the degree title offered in this kind of curriculum that emphasis mainly on the studies of a language by giving at the same time a major emphasis on the teacher training by the practice made during his training process.

As a consequence, the teacher course action is defined from the beginning training process in which the teacher is involved. This is surely given in response to the new trends of the teacher education, which involved the teacher in a permanent training based on the practice made at different schools where the future teacher has to be prepared for proposing different solutions that make him/her able to solve all the difficulties that can be presented in the school context.

\section{Conclusion}

As a conclusion, it can be affirmed after analyzing the resolution as the subject of the training of the English teacher is still quite complex and difficult to assume, therefore, it is unlikely to think that a norm like this can respond to the problems identified in the education received by the English teacher in the beginning.

Moreover, the resolution highlights the need to plan a learning program based on competencies, leaving aside other aspects which are inherent the teacher's education, such as its critical thinking towards the phenomena that happen in the school context in which he / she will have to implement the practice; the ethical - political considerations, the relevant events when developing the teacher's work, and other many factors in which it is necessary to remodel the first education received by the teacher in the country; something which implies checking the curricular design of the current curricula, and promoting the implementation of new reforms which point to strengthen the education received by the teacher.

This resolution, by the MEN, also expresses the intention of preparing a bilingual teacher. However, it evidences the consideration of implementing this need through an imposition which, although it is pertinent and necessary, it cannot ignore for reaching these language levels; it must have the enough and pertinent technological elements, infrastructure, work conditions, even for people who train teachers because, if there are not these minimal requirements, it will be difficult to get the demanded language level by this resolution

On the other hand, it is beneficial for future graduates that there is clarity in front of the title that this new teacher will receive, because the conditions of education offered to the English teacher do not offer a degree according to the occupational profile of this teacher, which It seems to be overcome in this resolution.

In the same way, there is a great emphasis on the teaching practice taking into account that the old standard recommended a practice of minimum one year, but it offered the possibility to develop it for a longer time, that depending on the criteria and the autonomy of each University institution.

As a contrast, the current reform obliges to increase the pedagogical component to a minimum of 50 credits, thus making it the main axis to be taken into account within a demanding curriculum in the same way, to make an exhaustive follow-up to all those acts that affect this process.

On the other hand, it draws attention to the way in which this rule does not take into account the particularities of 
the regions, without stopping to analyze the specific needs of each location in Colombia, as well as the individual conditions presented by different types of populations, such as the displaced, people with disabilities and immigrants, who require a different education, therefore, there particularities should be considered in the teacher's learning plan.

Finally, it is necessary to add, in front of the reality and the complex challenges offered by the current society of the global context, the need to have an urgent debate about the training processes received by the English teacher, which should be framed by serious and fundamental arguments conducive to the enrichment of the teaching, received by this teacher in the Colombian context.

\section{References}

Burns, A. (2009). Action research in second language teacher education. In A. Burns, \& J. C. Richards (Eds.). The Cambridge Guide to Second Language Teacher Education (pp. 289-297). Cambridge, UK: Cambridge University Press.

Graddol, D. (2006). English Next. Why global English may mean the end of "English as a Foreing Language". United Kingdom. British Council. Retrieved from http://vigdis.hi.is/sites/vigdis.hi.is/files/images/eina ngrun_enskuma elandi_folks.pdf

Kumaravadivelu, R. (2003). Beyond Methods: Macrostrategies for Language Teaching. New Haven. Yale University Press.

Larsen-Freeman, D., \& Long, M. (1991). Introducción al estudio de la adquisición de segundas lenguas. Madrid. Gredos.

Ministry of National Education. (2016). Resolución 02041 febrero 3 de 2016. República de Colombia. Ministerio de Educación Nacional Retrieved from www.mineducacion.gov.co/1759/articles-356982_recurso_1.pdf

Nunan, D. (2005). Syllabus Design. Oxford. Oxford University Press.

Nunan, D. (2005). The Learner-Centred Curriculum: A Study in Second Language Teaching (5th ed.). Cambridge. Cambridge University Press.

OCDE. (2002). Project DeSeCo: Définitions et sélection des compétences. Fondements theóriques et conceptuels. France. Document de strategie. Retrieved from https://www.oecd.org/pisa/35693273.pdf

Richards, J. (2012). The Context of Language Teaching, Cambridge (10th ed.). Cambridge. Cambridge University Press.

Richards, J., \& Rodgers, T. (2001). Approaches and Methods in Language Teaching. Second Edition. Cambridge. Cambridge University Press. https://doi.org/10.1017/CBO9780511667305

Sánchez, A. (2004). Enseñanza y aprendizaje en la clase de idiomas. Madrid. Sociedad General Española De Librería.

Sánchez, A. (2009). La enseñanza de idiomas en los últimos cien años. Métodos y enfoques. Madrid. Sociedad General Española De Libreria

Wallace, M. (1998). Action Research for Language Teachers. Cambridge. Cambridge University Press.

\section{Copyrights}

Copyright for this article is retained by the author(s), with first publication rights granted to the journal.

This is an open-access article distributed under the terms and conditions of the Creative Commons Attribution license (http://creativecommons.org/licenses/by/4.0/). 